\title{
A CRIAÇÃO DAS LICENCIATURAS CURTAS NO BRASIL
}

Thiago Rodrigues Nascimento (UERJ/FAPERJ)

O ano de 1964 entrou para a história brasileira como aquele em que se iniciou a mais longa ditadura de nosso país. Em março deste ano um golpe militar depôs o presidente eleito João Goulart, dando início a 21 anos de regime ditatorial. Imediatamente após o golpe, os novos dirigentes do país se organizaram para pensar as principais reformas que seriam necessárias na educação. Dermeval Saviani (2008) analisa em trabalho recente os simpósios organizados pelo Instituto de Estudos Políticos e Sociais (IPES) em dezembro de 1964 e o Fórum "A Educação que nos convém”, realizado entre outubro e novembro de 1968. Estes encontros pavimentaram um caminho que seria, posteriormente, seguido pelos formuladores das políticas educacionais, contribuindo para a elaboração de uma "visão pedagógica assumida pelo regime militar". Saviani (2008, p. 297) denomina esta orientação como "concepção produtivista da educação", incorporada à legislação do ensino e baseada em alguns pontos principais, como: princípios de racionalidade técnica, eficiência e produtividade, "máximo resultado com o mínimo dispêndio", valorização dos aspectos quantitativos em detrimento da qualidade do ensino e favorecimento da participação privada nas atividades de ensino.

Assim, o governo militar propôs e implantou uma série de reformas, em todos os níveis de ensino, da educação básica à universidade entre 1968 e 1971 (GERMANO, 2008, p. 324). Estes anos, profundamente importantes para a constituição da política educacional que guiaria o ensino no Brasil durante as décadas seguintes, foram marcados pelo gradativo fechamento político do país, a partir da publicação dos diferentes Atos Institucionais (AI), sobretudo, o AI-5, editado em dezembro de 1968. Período que se caracteriza pela sistematização do aparato repressivo e perda das liberdades individuais e coletivas, tortura, luta armada e pelo chamado "Milagre Econômico". Neste momento conturbado da cena política nacional, foram realizadas reformas no Ensino Superior e do Ensino de $1^{\circ}$ e $2^{\circ}$ graus que alteraram profundamente sua organização. Uma das modificações foi à criação das licenciaturas curtas em outubro de 1964 por meio de Indicação, do Conselho Federal de Educação, proposta pelo Conselheiro Newton Sucupira. É este documento que ora apresentamos.

A escolha deste documento não é aleatória, mas deriva da ausência de pesquisas que abordem a trajetória das licenciaturas de curta duração nas diferentes regiões do Brasil. Trata-se de um documento de difícil acesso, já que não se encontra digitalizado e está disponível para consulta apenas nas bibliotecas de algumas instituições de ensino superior. A Indicação $\mathrm{s} / \mathrm{n}$, intitulada, Sobre o exame de suficiência e formação do professor polivalente para o ciclo ginasial, versa sobre uma questão cara a educadores ao longo da primeira metade do século XX (e que, certamente, persiste até os nossos dias): a carência de professores de determinadas disciplinas e em algumas regiões.

Segundo a Indicação, "[...] a escola média brasileira [vinha] se defrontando com sério obstáculo ao seu processo de expansão, isto é, o sensível déficit de pessoal qualificado, o que obriga a improvisação de professores em detrimento dos padrões de ensino" (SUCUPIRA, 1964, p. 107). Os índices de escolaridade, segundo o texto de 1964, haviam crescido significativamente, mas sem uma política de formação de professores que correspondesse às novas necessidades da escola brasileira. A historiografia da educação aponta os anos 1930 como marco inicial para o processo de construção de um sistema nacional de ensino. Nestes anos, se estabeleceram as primeiras Faculdades de Filosofia, 
Ciências e Letras, responsáveis por formar, em nível superior, os professores. Entretanto, como demonstram diferentes estudos e trabalhos publicados entre os anos de 1950 e 1960 na Revista Brasileira de Estudos Pedagógicos (RBEP), estas instituições ainda não formavam professores em número suficiente para suprir as carências de docentes.

Para além da dificuldade das Faculdades de Filosofia em construírem seções de Ciências ou Matemática, por exemplo, é preciso destacar a concentração destas nos grandes centros urbanos, gerando um agrupamento de formados, em certas áreas, e uma carência constante em outras ${ }^{1}$. Romanelli (2007, p. 124) esclarece que em 1958 dos 4.419 professores registrados no Ministério da Educação para exercício do magistério no ensino secundário, apenas 724 tinham sido diplomados em Faculdades de Filosofia. Sobre a desproporção entre o número de formados nessas faculdades e aqueles que efetivamente exerciam o magistério a autora aponta, a partir da leitura de artigo de Jaime Abreu intitulado Status do Professor de Ensino Médio no Brasil e publicado na RBEP, que até "[...] 1960 eram 41.033 os diplomados em Faculdades de Filosofia contra um registro de apenas 5.395 para o exercício da docência." (ABREU, 1960, p. 96 Apud ROMANELLI, 2007, p. 124).

Jaime Abreu (1961), em Relatório apresentado no Encontro Regional de Educadores Brasileiros organizado pelo Ministério da Educação e Cultura em janeiro de 1961, destacava como uma das deficiências da educação brasileira o despreparo dos professores. Segundo o educador:

Quanto ao magistério, há grande número de integrantes dele sem formação própria nem ingresso qualificado para o desempenho da função, vivendo do preenchimento de formas de licença docente, a título precário, que se eternizam, ou de experiências de breves "aperfeiçoamentos" que não resolvem. (ABREU, 1961, p 17).

Os "exames de suficiência" foram adotados para a seleção de professores para atuação no nível secundário. Exigiam-se destes profissionais o mínimo de capacitação para lecionar. No caso da História, por exemplo, o conhecimento da matéria a ser ensinada não era tão importante, sabendo ler e escrever seriam, os selecionados, capazes de lecionar a disciplina escolar História. Sobre este aspecto destacou o professor Imídio Giuseppe Nérici (1957, p. 216), em artigo publicado originalmente no Jornal "Correio da Manhã" do Rio de Janeiro, "[...] até bem pouco tempo exigia-se do candidato ao magistério secundário que conhecesse a disciplina a lecionar e nada mais. Não se exigia a mínima preparação didática". Os professores eram selecionados nas mais diferentes áreas do conhecimento, Direito, Medicina e outras disciplinas de cunho liberal. Ao mesmo tempo em que surgiram grandes mestres, autodidatas, em sua maioria, outros não tão capazes eram responsáveis por ministrar a História, Ciências e Matemática, dentre outras, para as gerações futuras. "O sistema educacional brasileiro deparava-se, assim, com o grande desafio de preparar em curto prazo um número de professores, que suprissem as necessidades do magistério em termos não só de quantidade, e como também de qualidade.” (FERREIRA, 1982, p. 9). É a esta tarefa que se propõe a Indicação de Sucupira.

A licenciatura curta surgiu, neste momento, em "caráter experimental" e emergencial. A prioridade deveria ser a política de valorização e reformulação das Faculdades de Filosofia e suas licenciaturas e a "aplicação sistemática do exame de suficiência tendo em vista o maior número de professores a curto prazo". A perspectiva era a do mínimo por menos, isto é, o mínimo de qualificação necessária ao exercício da atividade docente pelo menor custo e tempo possíveis. Nesta perspectiva mais valeria uma formação aligeirada do que formação alguma. Na supracitada Indicação o relator apresenta 
o setor das Ciências da Natureza e da Matemática como o mais carente em termos de formação de professores e defende "[...] a criação de um professor polivalente para o ciclo ginasial, de Ciências Naturais e Matemática e Ciências Sociais". Segundo Sucupira (1964).

Esta figura do professor polivalente se justificaria sob vários aspectos: em primeiro lugar o professor ginasial não há de ser um especialista puro; em segundo lugar, do ponto de vista pedagógico formativo o ideal seria que, no primeiro ciclo, o mesmo mestre se ocupasse de várias matérias; finalmente, porque contribuiria para resolver o problema da falta de professores. (SUCUPIRA, 1964, p. 111).

A ênfase recaía sobre o aspecto quantitativo do problema em detrimento do qualitativo, não seria preciso que o professor do ensino das primeiras séries tivesse formação aprofundada. Um professor habilitado, mesmo que minimamente, a ensinar um bloco de disciplinas diminuiria a carência de profissionais. Uma vez mais aparece a lógica do mínimo pelo menos. Uma diminuição do período de integralização da licenciatura de quatro para três anos e um acúmulo de conteúdos a serem vistos neste curso espaço de tempo. (FERREIRA, 1982, p. 17). As licenciaturas de $1^{\circ}$ Ciclo seriam: a de Letras, compreendendo o ensino de Português e de uma língua viva; a de Estudos Sociais, habilitando ao magistério de História, Geografia e Organização Política e Social do Brasil; a de Ciências, para o ensino de Ciências Físico-Biológicas, Iniciação às Ciências e Matemática. (SUCUPIRA, 1964, p. 111).

\section{Referências}

ABREU, Jaime. Ensino médio em geral e Ensino Secundário. Revista Brasileira de Estudos Pedagógicos, v. XXXV, n. 81, p. 7-24, Jan./Fev. 1961.

FERREIRA, Eunice Freitas. Licenciatura de Curta Duração: solução emergencial ou definitiva? 1982. 90 f. Dissertação (Mestrado em Educação) - Departamento de Educação, PUC/RJ, 1982.

GERMANO, José Willington. O discurso político sobre a educação no Brasil autoritário. Cadernos Cedes, Campinas, v. 28, n. 76, p. 313-332, set./dez. 2008.

NÉRICI, Imídio Giuseppe. Formação do professor do Ensino Secundário. Revista Brasileira de Estudos Pedagógicos, v. XXVII, n. 65, p. 216-222, Jan./Mar. 1957.

ROMANELli, Otaíza de Oliveira. História da Educação no Brasil (1930/1973). 32a edição. Petrópolis: Vozes, 2007.

SAVIANI, Dermeval. O legado educacional do Regime Militar. Cadernos Cedes, Campinas, v. 28, n. 76, p. 291-312, set./dez. 2008. 


\section{DOCUMENTO}

\section{SOBRE EXAME DE SUFICIÊNCIA E FORMAÇÃO DO PROFESSOR POLIVALENTE PARA CICLO GINASIAL}

\section{Aprovado em 9-10-1964, com restrições do Cons. ${ }^{\circ}$ Valnir Chagas, somente quando à duração da licenciatura polivalente}

A escola média brasileira vem se defrontando com sério obstáculo ao seu processo de expansão, o sensível déficit de pessoal docente qualificado, o que obriga a improvisação de professores em detrimento dos padrões de ensino.

Na década de 1953 - 1962 houve crescimento de mais de $100 \%$, e se as metas do Plano Nacional de Educação, relativas ao ensino médio fossem integralmente atingidas até 1970 teríamos um índice de escolaridade que importaria em verdadeira explosão educacional. Sobretudo, se levarmos em conta que não temos, ainda, na escola $15 \%$ da população em idade escolar correspondente. Mas, mesmo que essas metas não venham a ser alcançadas no prazo previsto, não resta dúvida que nosso sistema de ensino médio continuará em acentuada expansão, a julgar pelos índices de crescimento verificados nesta última década. Essa expansão, contudo, não se fará no ritmo desejado ou será menos entravada se não produzirmos professores em quantidade suficiente para assegurar o aumento da escolarização programado.

No entanto, apesar dos planos e previsões de desenvolvimento do sistema escolar de grau médio, tem-nos faltado uma política objetiva e eficaz na formação de professores a curto prazo. Se é verdade que o Plano Nacional de Educação destinava recursos para assistência técnica, compreendendo programas de treinamento para o magistério, o fato é que até o presente não se desenvolveu nenhum programa de emergência visando à ampliação imediata dos quadros da escola média.

Ora, de acordo com a própria lei das Diretrizes e Bases cabe ao Conselho Federal de Educação "adotar ou propor modificações e medidas que visem à expansão e ao aperfeiçoamento do ensino".

(art. 9. ${ }^{\circ}$, letra j). Está, assim, o Conselho no dever de gerir medidas que contribuam para a formação de uma política de treinamento de professores em face das exigências de expansão imediata da escola média brasileira. É neste sentido que apresentamos a presente indicação.

Sabemos que é problema capital do processo de expansão, em grande escala, de um sistema escolar, a preparação, a curto prazo, de professores em número suficiente e com o mínimo de qualificação necessária para tornar possível o crescimento quantitativo sem graves prejuízos para a qualidade do ensino. Por isso mesmo o problema deve ser equacionado em termos de qualidade e quantidade, ou seja, em função das exigências imediatas do aumento da rede escolar e do imperativo de se melhorar progressivamente o nível de ensino de uma escola cujas deficiências são notórias. O desafio que enfrentamos é, juntamente, de treinar o maior número de professores com o mínimo de habilitação necessária e no menor tempo possível.

Desde 1946 dispomos de dois sistemas de treinamento do magistério secundário e que foram consagrados pela Lei das Diretrizes e Bases: as Faculdades de Filosofia e os exames de suficiência. Os cursos destas faculdades constituem o processo normal de formação dos mestres da escola secundária e a elas estaria reservada a missão de preparar um corpo docente altamente qualificado. $\mathrm{O}$ exame de suficiência é a medida de emergência indispensável a que temos de recorrer a fim de prover a escola do professores de que necessita, na falta dos licenciados. 
À luz dessas premissas, julgamos que uma política de formação do magistério da escola média, visando a atender aos aspectos quantitativos e qualitativos de seu desenvolvimento, deveria perseguir esses dois objetivos: primeiramente valorizar os cursos da Faculdade de Filosofia, aperfeiçoando-os, reformulando algumas de suas licenciaturas, mediante um programa de assistência técnica e financeira com o fim de se constituir um professor de alto nível; em segundo lugar, aplicação sistemática de exame de suficiência tendo em vista o maior número de professores a curto prazo.

Quanto aos exames de suficiência, prestaram eles decisiva contribuição para o recrutamento de mestres da escola secundária no período que vai de 1946 a promulgação das Leis das Diretrizes e Bases. Segundo os dados fornecidos pela Diretoria do Ensino secundário, enquanto esses exames estiveram sob a responsabilidade da C.A.D.E.S., entre 1956 e 1960, inscreveram-se nos seus cursos 18.815 candidatos, dos quais foram aproveitados 7506.

Com o advento da Lei das Diretrizes e Bases, o exame de suficiência passou à competência das Faculdades de Filosofia nos termos do art. 117. Por se tratar de medida destinada a assegurar a expansão do ensino médio o Conselho promoveu sua regulamentação que foi logo convertida em portaria ministerial. Nessa regulamentação foram fixados critérios gerais orientando a realização desses exames a fim de que pudessem alcançar a eficácia desejada.

Feita a regulamentação desde dezembro de 1963, não se tomou ainda nenhuma providência no sentido de uma utilização sistemática dos exames de suficiência. Aliás, estes exames praticamente deixaram de funcionar desde a vigência da L.D.B. Ora, a experiência realizada pela C.A.D.E.S., com todos os seus possíveis defeitos, revelou que o exame de suficiência valeu como instrumento eficaz para o recrutamento de emergência de mestres da escola secundária em sua fase de crescimento.

Em nosso entender temos de apelar, nas condições atuais, para medidas de emergência dessa natureza se quisermos acelerar a expansão da nossa escola. A Inglaterra, depois da última guerra, para fazer face ao aumento da escolarização programado, utilizouse dos "Emergency training colleges", o que permitiu recrutar, em pouco tempo, grande número de mestres formados fora do sistema normal, em dois semestres, conseguindo deste modo prolongar mais um ano a escolaridade obrigatória. Portanto, o que se impõe é dinamizar e aperfeiçoar o sistema, aproveitando a experiência anterior. Para isso, sugerimos as seguintes medidas concretas a serem adotadas pelas autoridades competentes:

- Promover o levantamento das necessidades atuais dos professores nas diversas regiões do país e em função das previsões de aumento da escolaridade;

- Promover através da Diretoria de Ensino Secundário, uma reunião com os Diretores das Faculdades de Filosofia oficiais indicadas pelo Conselho com o fim de acertar providências tendentes a facilitar a realização dos exames de suficiência;

- Programar cursos intensivos de um a dois semestres destinados a preparar os candidatos ao exame de suficiência. Tais cursos poderiam ser realizados em convênio com as próprias Faculdades de Filosofia ou deslocando equipes de professores para as localidades onde não as houvesse. Neste caso seriam criados centros de treinamento nas regiões mais necessitadas. De imediato poderiam ser programados cursos durante as férias de verão.

No que se refere às Faculdades de Filosofia não se encontram elas em condições de fazer face à carência de professores, não obstante sua extraordinária expansão nas três décadas de sua existência. Em 1962 contávamos, no ensino médio, com um corpo docente de 83.075 pessoas que equivalem a 105.174 professores, se considerarmos os vários cursos em que frequentemente o mesmo indivíduo leciona. Considerando-se que o secundário 
compreende 73,4\% desse total e as disciplinas de letras e ciências que figuram nos outros ramos temos que a porcentagem de professores licenciados no ensino médio é ainda íntima. Em 1960 a Diretoria do Ensino Secundário acusava o registro definitivo de 20312 professores, dos quais somente 5395 eram licenciados, ou $26,5 \%$.

Se levarmos em conta a progressão dos índices de conclusão de curso de 1956 (1.300 licenciados) a 1961 (3.011) é de esperar que no qüinqüênio 1962/1966 teremos produzido pouco mais de 20.000 licenciados, numa estimativa grosseira. Número esse ainda insuficiente para as necessidades da escola, acrescendo que muitos são licenciados que não se dedicam ao ensino médio. Numa economia em desenvolvimento, onde as oportunidades ocupacionais para trabalhadores intelectuais qualificados são freqüentes e bem remuneradas, é natural que os melhores licenciados deixem o ensino por outras profissões mais rendosas.

Mas é no setor das Ciências Naturais e da Matemática onde se verificava a maior escassez de professores qualificados, justamente, por causa do número reduzido de cursos para esta ciência. Em 1962, nas 81 faculdades contavam-se apenas 11 cursos de Física, 7 de Química, 13 de História Natural e 25 de Matemática. Em 1961 diplomaram-se 51 licenciados em Física, 43 em Química , 225 em História Natural e 137 em Matemática, ao todo 456 licenciados perfazendo $15,1 \%$ do todo de 3011. No mesmo ano nos 10 estados das Regiões Norte e Nordeste diplomaram-se 15 licenciados em Matemática e nenhum em Física e Química. Atualmente existem dois cursos de Física e Química para aquelas duas regiões. Desde 1962 foram apresentados ao Conselho Federal de Educação pedidos de autorização para funcionamento de, apenas, dois cursos de Matemática, um de Física e outro de História Natural. Ora, Matemática e Ciências Físico-Biológicas são matérias obrigatórias para todo País no ciclo ginasial.

Além disso, as melhores faculdades nos cursos de Física, Química, História Natural e Matemática, se preocupam quase que exclusivamente em formar puros pesquisadores, sem levar em conta as exigências específicas da formação intelectual do mestre da escola secundária. Daí resulta um licenciado desinteressado do magistério secundário, orientandose, de preferência, para o ensino superior, a pesquisa, ou se dedicando a outras ocupações mais vantajosas na linha de sua especialidade.

Em face disso faz-se necessário a reformulação da licenciatura de ciências tendo em vista a preparação do professor da escola média, e, em particular, do primeiro ciclo. $\mathrm{O}$ Conselho ao determinar as cinco matérias obrigatórias criou uma nova disciplina, Ciências Físico-Biológicas, a qual se liga Iniciação às ciências. Como o nome está a indicar o seu conteúdo deve abranger noções de Física, Química e Biologia. Seria conveniente a instituição de uma licenciatura especialmente destinada à formação de professores desta disciplina. Por outro lado seria recomendável a criação de um professor polivalente para o ciclo ginasial, de ciências Naturais e Matemática e de Ciências Sociais, como de resto já tínhamos sugerido no Par. 314/63. Esta figura do professor polivalente se justificaria sob vários aspectos: em primeiro lugar o professor de ginasial não há de ser um especialista puro; em segundo lugar, do ponto de vista pedagógico formativo o ideal seria que, no primeiro ciclo, o mesmo mestre se ocupasse de várias matérias; finalmente, porque contribuiria para resolver o problema da falta de professores.

Assim, teríamos três licenciaturas para o essencial do ensino no primeiro ciclo: a de Letras, compreendendo o ensino de Português e uma língua viva; a de Estudos Sociais, habilitando ao magistério de História, Geografia e Organização Política e Social Brasileira; a de Ciências, para o ensino de Ciências Físico-Biológicas, Iniciação às Ciências, e Matemática. Estas licenciaturas seriam específicas do ciclo ginasial, embora seus titulares pudessem ensinar em segundo ciclo enquanto não houvessem professores de quatro anos 
em número suficiente. Estes licenciados poderiam posteriormente tirar os créditos necessários à licenciatura que os habilitasse ao ensino definitivo do ciclo colegial ou do curso superior.

O tempo de duração destas licenciaturas poderia ser de três anos. Justifica-se esta redução uma vez que o Bacharelado preparava indiferentemente o professor e o especialista neste mesmo espaço de tempo. Agora que o currículo mínimo das matérias pedagógicas reduziu sensivelmente o número destas matérias, algumas delas podendo ser ministradas num semestre, julgamos possível preparar-se um professor para o ciclo ginasial em três anos.

Assim, como se procedeu na determinação dos currículos mínimos sugerimos que o conselho se dirija às instituições credenciadas no sentido de que enviem sugestões para a elaboração do currículo mínimo destas licenciaturas. Em particular para a licenciatura de ciências devemos solicitar a elaboração do I.B.E.C.C., instituição especializada no ensino de ciências no curso secundário.

Finalmente, para que possamos aumentar o número de professores de Ciências, impõe-se que o Ministério da Educação desenvolva um programa de assistência técnica e financeira a fim de promover a implantação da Licenciatura de Ciências no maior número possível de Faculdades de Filosofia. (aa.) Newton Sucupira, relator. - A. Almeida Júnior, Demerval Trigueiro Celso Kelly, Rubens Maciel, José Montello.

Fonte:

SUCUPIRA, Newton. Sobre o exame de suficiência e formação do professor polivalente para o ciclo ginasial. Documenta, n. 31, p. 107-111, 1964.

\footnotetext{
${ }^{1}$ Ferreira (1982, p. 50-51), citando um estudo do Instituto de Recursos Humanos da Fundação Getúlio Vargas sobre o curso superior de duração reduzida de 1976, destaca que as Faculdades de Filosofia, Ciências e Letras se concentravam nas regiões mais desenvolvidas economicamente. "Das 88 Faculdades de Filosofia existentes no país, 52 encontram-se localizadas em apenas seis Estados: Guanabara, São Paulo, Estado do Rio, Minas Gerais, Paraná e Rio Grande do Sul, englobando $80 \%$ da matricula nacional".
} 